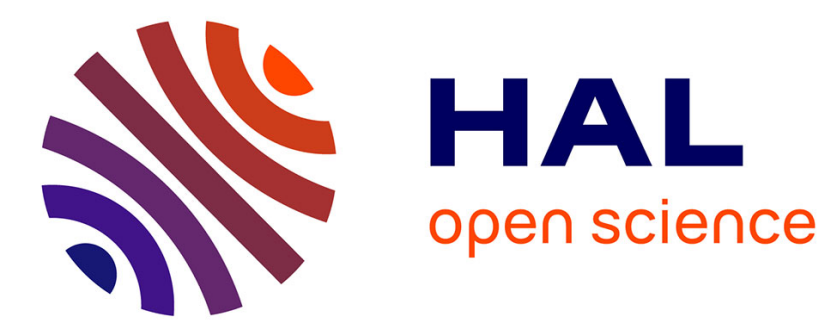

\title{
Optimal provision of a public good with costly exclusion
}

Nicolas Gravel, Michel Poitevin

\section{To cite this version:}

Nicolas Gravel, Michel Poitevin. Optimal provision of a public good with costly exclusion. Games and Economic Behavior, 2019, 117, pp.451-460. 10.1016/j.geb.2019.07.009 . hal-02283840

\section{HAL Id: hal-02283840 \\ https: / / hal-amu.archives-ouvertes.fr/hal-02283840}

Submitted on 11 May 2020

HAL is a multi-disciplinary open access archive for the deposit and dissemination of scientific research documents, whether they are published or not. The documents may come from teaching and research institutions in France or abroad, or from public or private research centers.
L'archive ouverte pluridisciplinaire $\mathbf{H A L}$, est destinée au dépôt et à la diffusion de documents scientifiques de niveau recherche, publiés ou non, émanant des établissements d'enseignement et de recherche français ou étrangers, des laboratoires publics ou privés. 


\title{
Optimal provision of a public good with costly exclusion
}

Nicolas Gravel (corresponding author)

Centre de Sciences Humaines \& Aix-Marseille School of Economics

2, Dr. Abdul Kalam Road, 110011 Delhi, India

nicolas.gravel@csh--delhi.com

Michel Poitevin

Université de Montréal, CIREQ, and CIRANO

3150, rue Jean-Brillant, bureau C-6042,

C.P. 6128, succursale Centre-ville Montréal (Québec) H3C 3J7

michel poitevin@umontreal.ca

\begin{abstract}
We examine the problem of providing a non-rival and excludable public good to individuals with the same preferences and differing contributing capacities. Exclusion from the public good is costly in the sense that if two different quantities of the public good are consumed in the community, then the sum of the costs of providing the two quantities must be borne. By contrast, costless exclusion only requires the cost of the largest quantity consumed of the public good to be financed. We show that despite its important cost, providing public goods in different quantities is often part of any optimal provision of public good when the public authority is imperfectly informed about the agents' contributive capacities. In the specific situation where individuals have an additively separable logarithmic utility function, we provide a complete characterization of the optimal exclusion structure in the two-type case. We also show that the preference for such a costly exclusion is more likely when the heterogeneity in the population or income is large, and when the aversion to utility inequality is important.
\end{abstract}

Keywords: Mechanism design, asymmetric information, public goods, costly exclusion.

JEL classification codes: D78, H41 


\section{Introduction}

There is a significant literature (see, e.g., Drèze (1980), Fang and Norman (2010), Fraser (1996), Hellwig (2003, 2005, 2007), Moulin (1994), and Norman (2004)) that has addressed the problem of providing non-rival but excludable public goods to individuals with varying level of contributive capacities. Typical examples of non-rival and excludable public goods are cable television, internet access or, up to the congestion point, highways. An important conclusion of the literature is that, while the non-rivalry of the public good makes exclusion undesirable from a normative point of view in a first best environment, exclusion can be part of any optimal allocation of private and public goods when the information on individual preferences and/or contributive capacities is private.

Two types of assumptions on the possibilities for exclusion from the consumption of public goods have been considered. Fraser (1996), Hellwig (2003, 2005, 2007) define exclusion as a zero-one matter: an individual has either full access to the available quantity of public good or no access at all. The cost of financing the public good is the cost of this available quantity. Drèze (1980), Fang and Norman (2010), Moulin (1994), or Norman (2004) assume that individuals have access to any quantity of public good that does not exceed the maximal available quantity. The cost of financing the public good is then the cost of the maximal available quantity.

We consider the case of a public good with the property that if two distinct quantities of public good are consumed by different individuals, the sum of their costs must be financed. This form of exclusion is obviously more costly than when only the maximal available quantity must be financed. But it is more general than when exclusion is a zero-one matter since we allow individuals that do not consume the maximum available quantity to still consume some positive amount. We refer to our form of exclusion as costly exclusion, as opposed to costless exclusion when only the maximal available quantity must be financed. An example of a public good with costly exclusion could be a police force. Once a police force is created, it is somewhat difficult to exclude some individuals from the full protection against crime that the police force provides. However, it is possible to create several distinct police forces -of various sizes- in different geographically located "jurisdictions". Inhabitants of these jurisdictions will then benefit from the protection provided by their police force. But such a duplication of police forces is obviously quite costly. Yet, our main conclusion is that costly exclusion can nonetheless be recommended on normative ground 
when individuals differ and when information on their contributive capacities is not publicly available.

We assume that individuals have the same preference for a private good and a public good, and are partitioned into two types based on their (unobserved) income. We show in this setting that there are only two types of exclusion structure that can be chosen by a Paretian mechanism designer. The first one, without exclusion, involves putting everybody in one jurisdiction and making them consume the same amount of public good and pay the same tax. The other, with exclusion, put the rich and the poor in two distinct jurisdictions with different packages of tax and public good, and allows for subsidization across jurisdictions.

Exclusion has two main benefits. First, it allows redistribution from the rich to the poor through cross-subsidization. Second, it permits to offer each type a public good and tax package that is in line with the type's preferences. The trade off between these benefits and the cost of duplicating the public good determines the optimal choice of jurisdiction structure by the mechanism designer.

We characterize the Pareto frontier associated with each exclusion structure. We also illustrate the analysis in the case where preferences are logarithmic in both the public good and the private good. We identify for this case the set of parameter values for which exclusion is optimal for both a Maxmin and a Utilitarian objective. Exclusion happens to be more likely when the heterogeneity in contributive capacities is important. Indeed, with no exclusion, the mechanism designer cannot differentiate the amount of public good provided to each type and cannot operate any redistribution. Hence, when heterogeneity is important, the mechanism designer prefers creating two distinct jurisdictions. We also show that the inequality averse Maxmin mechanism designer is more likely to favor exclusion than is the equality neutral Utilitarian one. Exclusion allows in effect the mechanism designer to tax the rich jurisdiction and to subsidize the poor one. This possibility of redistribution is obviously more favored by the Maxmin mechanism designer than by the Utilitarian one. We show however that if we do not allow for cross subsidization in the structure with exclusion, a Maxmin mechanism designer always pool all individuals in one jurisdiction, while a Utilitarian planner may still choose to exclude if the heterogeneity between types is significant enough.

The next section presents the model and some general results. Section 3 presents more results for specific preferences and Section 4 concludes. All proofs 
are relegated to the Appendix.

\section{General analysis}

There are $n \geq 2$ individuals that are split in two types: $n_{1}$ "rich" individuals, with income $w_{1}$, and $n_{2}$ "poor" individuals, with income $w_{2}$ (with $w_{1} \geq w_{2}$ ). We denote by $w^{i} \in\left\{w_{1}, w_{2}\right\}$ the income of individual $i$. Each individual consumes a public good $(z)$ and a private good $(x)$. The public good is non-rival in consumption but is excludable in the sense that its consumption may be made contingent upon the fact of belonging to a specific "jurisdiction". Specifically, exclusion can be made by partitioning the set $N$ of individuals into pairwise disjoint sets $N_{j}$ (for $j=1, \ldots, l$ for some number $l \in\{1, \ldots, n\}$ such that $\bigcup_{j=1}^{l}$ $\left.N_{j}=N\right)$. Any set $N_{j}$ of this partition is interpreted as a "jurisdiction" and the collection of $l$ such sets $\left\{N_{j}\right\}_{j=1}^{l}$ is interpreted as an exclusion structure. For any structure $\left\{N_{j}\right\}_{j=1}^{l}$ and any individual $i \in N$, we denote by $j(i)$ (with $j(i) \in\{1, \ldots, l\}$ ) the (unique) jurisdiction of $i$. We refer to the trivial structure obtained when $l=1$ and all individuals are pooled together as no-exclusion. An allocation of public and private goods for the exclusion structure $\left\{N_{j}\right\}_{j=1}^{l}$ is defined as a list $\left(z_{1}, \ldots, z_{l} ; x^{1}, \ldots, x^{n}\right) \in \mathbb{R}_{+}^{l+n}$ where $z_{j}$ is the consumption of public good in jurisdiction $j$ (for $j \in\{1, \ldots, l\}$ ) and $x^{i}$ is the consumption of private good by individual $i$. An allocation of public and private goods is feasible for the exclusion structure $\left\{N_{j}\right\}_{j=1}^{l}$ if it verifies the aggregate budget constraint:

$$
\sum_{j \in\{1, \ldots, l\}} z_{j}+\sum_{i \in N} x^{i} \leq n_{1} w_{1}+n_{2} w_{2}
$$

If we denote by $t^{i}=w^{i}-x^{i}$ the tax paid by individual $i$, one can write equivalently the budget constraint as $\sum_{j \in\{1, \ldots, l\}} z_{j} \leq \sum_{i \in N} t^{i}$. The specification of the budget constraint makes clear that subsidization across jurisdictions is possible, and, as we shall see, desirable.

Individuals' preferences are given by the same continuously differentiable, strictly increasing and concave function $U: \mathbb{R}_{+}^{2} \rightarrow \mathbb{R}$. We shall also make use of the dual representation of the individuals' preferences. Specifically, for any combination of public good and private good prices $p_{z}$ and $p_{x}$, net income $w-t$ and utility level $u$, we denote by $V\left(p_{z}, p_{x}, w-t\right)$ and $E\left(p_{z}, p_{x}, u\right)$ the indirect utility and expenditure functions (respectively). The Marshallian and Hicksian demands are denoted by $z^{M}\left(p_{z}, p_{x}, w-t\right), x^{M}\left(p_{z}, p_{x}, w-t\right), z^{H}\left(p_{z}, p_{x}, u\right)$ and 
$x^{H}\left(p_{z}, p_{x}, u\right)$ respectively. Given the assumptions imposed on $U$, all these functions are well-defined and differentiable with respect to their arguments. We make the additional assumption that the two goods are normal so that their Marshallian demands are both increasing in income. It is well-known that this assumption implies that:

$$
\frac{\partial U(\bar{z}, \bar{x}) / \partial z}{\partial U(\bar{z}, \bar{x}) / \partial x}>\frac{\partial U(\bar{z}, \widehat{x}) / \partial z}{\partial U(\bar{z}, \widehat{x}) / \partial x} \text { for any } \bar{z}>0 \text { and } \bar{x}>\widehat{x}>0
$$

Inequality (2) has the important implication that, if one represents the individual's preferences in the space $(z, t)$ by the function $U\left(z, w_{i}-t\right)$, then these preferences satisfy the familiar single-crossing property that the slope of the indifference curves is increasing with respect to income.

Allocations of public and private goods are evaluated by a Mechanism Designer (MD) who uses a Pareto inclusive criterion. Such a designer considers the allocation $\left(z_{1}, \ldots, z_{l} ; x^{1}, \ldots, x^{n}\right)$ of the exclusion structure $\left\{N_{j}\right\}_{j=1}^{l}$ to be weakly better than the allocation $\left(z_{1}^{\prime}, \ldots, z_{l^{\prime}}^{\prime} ; x^{\prime 1}, \ldots, x^{\prime n}\right)$ of the structure $\left\{N_{j}^{\prime}\right\}_{j=1}^{l^{\prime}}$ if and only if $W\left(U\left(z_{j(1)}, x^{1}\right), \ldots, U\left(z_{j(n)}, x^{n}\right)\right) \geq W\left(U\left(z_{j(1)}^{\prime}, x^{\prime 1}\right), \ldots, U\left(z_{j(n)}^{\prime}, x^{\prime n}\right)\right)$ for some (social welfare) function $W: \mathbb{R}^{n} \rightarrow \mathbb{R}$ increasing with respect to each of its argument. Specific functions that we use below are $W\left(u_{1}, \ldots, u_{n}\right)=u_{1}+\ldots .+u_{n}$ (Utilitarianism) and $W\left(u_{1}, \ldots, u_{n}\right)=\min \left\{u_{1}, \ldots, u_{n}\right\}$ (Maxmin).

As is well-known from basic public economics, if individuals' utility and income were public information, the problem solved by the MD would be easy. Non-rivalry in consumption means that it is wasteful to have different individuals consuming different quantities of the public good, and hence, the MD always decides to pool all individuals in the same jurisdiction and asks them to pay a personalized (Lindahl) tax.

Things are clearly different if all the relevant information is not available to the MD. We consider here the case where the MD does not know the individuals' type. In such a case, the MD is unable to levy personalized taxes on individuals who consume the same quantity of the public good because these individuals are informationally indistinguishable. The MD can, however, provide individuals with different packages of tax and public good levels by assigning them to different jurisdictions. Doing so is costly because the MD must replicate the cost of providing the public good.

Let us examine the problem faced by the MD of choosing an exclusion structure $\left\{N_{j}\right\}_{j=1}^{l}$ (for some $l \in\{1, \ldots, n\}$ ) and a feasible allocation of the private and 
the public goods for the structure that maximizes its social objective, subject to the constraint that every individual prefers his/her preferred package of public good and tax to any other. The analysis of this problem proceeds in two steps.

In the first step, for any exclusion structure $\left\{N_{j}\right\}_{j=1}^{l}$, the MD solves the program: ${ }^{1}$

$$
\begin{array}{rl}
\Psi\left(\left\{N_{j}\right\}_{j=1}^{l}\right)=\max _{z_{1}, t_{1}, \ldots, z_{l}, t_{l}} & W\left(U\left(z_{j(1)}, w^{1}-t_{j(1)}\right), \ldots, U\left(z_{j(n)}, w^{n}-t_{j(n)}\right)\right) \\
\text { s.t. } & \sum_{j=1}^{l} z_{j} \leq \sum_{j=1}^{l} \# N_{j} t_{j} \\
& U\left(z_{j(i)}, w^{i}-t_{j(i)}\right) \geq U\left(z_{j^{\prime}}, w^{i}-t_{j^{\prime}}\right) \\
\text { for all } j^{\prime} \in\{1, \ldots, l\}, i \in N .
\end{array}
$$

Inequality (4) is the budget constraint, while inequalities (5) are the incentive constraints.

The second step of the analysis consists in choosing the exclusion structure $\left\{N_{j}\right\}_{j=1}^{l}$ that maximizes the value of $\Psi$. An obvious candidate is the no-exclusion structure. Studying Program (3) without exclusion is easy because there are no incentive constraints (5). In that case, all individuals must pay the same tax and the budget constraint becomes $z=n t$. Program (3) thus becomes:

$$
\Psi(N)=\max _{t \in\left[0, w_{2}\right]} W\left(U\left(n t, w^{1}-t\right), \ldots, U\left(n t, w^{n}-t\right) .\right.
$$

The necessary (and sufficient if $W$ and $U$ are concave) first-order condition for an interior solution $t^{*}$ is:

$$
n \frac{\bar{W}_{z}^{*}}{\bar{W}_{x}^{*}}=1
$$

where $\bar{W}_{k}^{*}=\left[\sum_{i \in N}\left[\partial W(.) / \partial u_{i}\right] U_{k}\left(n t^{*}, w^{i}-t^{*}\right)\right] / n$ for $k=z, x$, is the average social marginal utility of good $k$ at the optimal choice. Condition (7) looks somewhat like a Samuelson condition that characterizes optimal allocations of private and public good when information is publicly available. Indeed, Condition (7) says that the sum of the ratio of the (socially weighted) average marginal utility of the public good over the (socially weighted) average marginal utility of the private good must equal the marginal rate of transformation of 1 . If the ratio

\footnotetext{
${ }^{1}$ We omit the feasibility constraints that $w_{i}-t_{j(i)} \geq 0$ for all $i$.
} 
of the (socially weighted) average marginal utility of the public good over the (socially weighted) average marginal utility of the private good was coinciding with the average marginal rate of substitution, then first-best optimality would obtain. There is no reason however to expect such a coincidence in general. ${ }^{2}$

The single-crossing property greatly simplifies the analysis of Program (3) in the case where exclusion is present. Using results from Athey (2002), one can show that, for any exclusion structure that maximizes $\Psi$, public good levels must be weakly increasing in types. This implies that if two individuals with distinct income belong to a jurisdiction, then so must all individuals with income weakly between that of those two. Moreover, because consumption is non rival, it is impossible to have two distinct jurisdictions with the same level of public good. Otherwise, it would be optimal to merge the two jurisdictions and save on the cost of providing the public good. In our two-type setting, this means that only two jurisdiction structures can optimally be chosen: one with no exclusion, and one with exclusion where each type lives in a distinct jurisdiction.

An additional property of an optimal structure that involves exclusion is that the (upward) incentive constraint of the poor does not bind. In effect, if members of the poor jurisdiction were indifferent between what they get in their jurisdiction and what they would get by moving to the rich one, then the MD could produce a Pareto improvement by assigning all the poor to that richer jurisdiction. Doing so, the poor would pay the higher taxes that the rich pay but would get more public good. The MD would collect more tax revenues and could use them to improve welfare. The following proposition summarizes these results.

Proposition 1. Let $U$ be a utility function in $\mathcal{U}$ and assume that $\left\{N_{j}^{*}\right\}_{j=1}^{l}$ is a jurisdiction structure with public goods and taxes $\left(z_{j}^{*}, t_{j}^{*}\right)_{j=1}^{l}$ that maximizes the function $\Psi$ defined by Program (3).

1. If two jurisdictions $j$ and $j^{\prime} \in\{1, \ldots, l\}$ are such that $w^{i} \leq w^{i^{\prime}}$ for some individuals $i \in j$ and $i^{\prime} \in j^{\prime}$, then it must be that $z_{j}^{*} \leq z_{j^{\prime}}^{*}$.

2. There cannot be two distinct jurisdictions $j$ and $j^{\prime} \in\{1, \ldots, l\}$ such that $z_{j}^{*}=z_{j^{\prime}}^{*}$

3. If two jurisdictions $j$ and $j^{\prime} \in\{1, \ldots, l\}$ are such that $z_{j}^{*}<z_{j^{\prime}}^{*}$, with $j(i)=j$, it must be that $U\left(z_{j}^{*}, w^{i}-t_{j}^{*}\right)>U\left(z_{j^{\prime}}^{*}, w^{i}-t_{j^{\prime}}^{*}\right)$.

We now analyze the Pareto frontiers of these structures. The Pareto frontier associated with the no-exclusion structure is a curve lying between two extreme

\footnotetext{
${ }^{2}$ An important case where such a coincidence would arise is when the utility is additively separable and linear with respect to the private good.
} 
points at which a representative member of each of the two types gets his "ideal utility" associated with his favorite tax.

The favorite tax rate $t_{i}^{n *}$ of a type $i=1,2$ individual in the no-exclusion structure solves

$$
\max _{t} U\left(n t, w_{i}-t\right)
$$

It is therefore defined by $t_{i}^{n *}=\min \left[z^{M}\left(1 / n, 1, w_{i}\right) / n, w_{2}\right]$. Individual 2's ideal utility level is therefore $u_{2}^{n *}=V\left(1 / n, 1, w_{2}\right)$ while individual 1's ideal utility is $u_{1}^{n *}=V\left(1 / n, 1, w_{1}\right)$ if $z^{M}\left(1 / n, 1, w_{1}\right) / n \leq w_{2}$ and is $u_{1}^{n *}=U\left(n w_{2}, w_{1}-w_{2}\right)$ otherwise. For any $u_{1} \in\left[U\left(n t_{2}^{n *}, w_{1}-t_{2}^{n *}\right), U\left(n t_{1}^{n *}, w_{1}-t_{1}^{n *}\right)\right]$, the function $\Theta^{n}$ can be defined by:

$$
\Theta^{n}\left(u_{1}\right)=\max _{t \in\left[0, w_{2}\right]} U\left(n t, w_{2}-t\right) \text { s.t. } U\left(n t, w_{1}-t\right) \geq u_{1} .
$$

It can be checked that $\Theta^{n}$ is decreasing and concave on its domain. Furthermore, since $w_{1} \geq w_{2}, \Theta^{n}$ is such that the utility of the rich is larger than that of the poor. It is therefore impossible to be utility-egalitarian in this second-best world without exclusion. We also note that $\Theta^{n}$ only depends on the total number of individuals and is independent of the relative number of each type.

The Pareto frontier for the structure with exclusion that is relevant for the comparison with the no-exclusion case can be described by the following program:

$$
\begin{array}{rl}
\Theta^{e}\left(u_{1}\right)=\max _{z_{1}, z_{2}, t_{1}, t_{2}} & U\left(z_{2}, w_{2}-t_{2}\right) \\
\text { s.t. } \quad & z_{1}+z_{2} \leq n_{1} t_{1}+n_{2} t_{2} \\
& U\left(z_{1}, w_{1}-t_{1}\right) \geq u_{1} \\
& U\left(z_{1}, w_{1}-t_{1}\right) \geq U\left(z_{2}, w_{1}-t_{2}\right)
\end{array}
$$

Thanks to Proposition 1, we ignore the part of the Pareto frontier where the incentive constraint of the poor binds. One can show that the bundle of public and private goods of the rich agent is not distorted. This bundle is nothing else than the Hicksian demand bundle of the public and private goods associated with a (Lindahl) price of the public good of $1 / n_{1}$ and the utility level of $u_{1}$. 
Program (9) then becomes:

$$
\begin{array}{rl}
\Theta^{e}\left(u_{1}\right)=\max _{z_{2}, t_{2}} & U\left(z_{2}, w_{2}-t_{2}\right) \\
\text { s.t. } & z_{2}-n_{2} t_{2} \leq n_{1}\left(w_{1}-E\left(1 / n_{1}, 1, u_{1}\right)\right) \\
& u_{1} \geq U\left(z_{2}, w_{1}-t_{2}\right)
\end{array}
$$

For a sufficiently high $u_{1}$, the incentive constraint (11) does not bind, and Program (10) reduces to:

$$
\begin{aligned}
& \Theta^{e}\left(u_{1}\right)=\max _{z_{2}, x_{2}} U\left(z_{2}, x_{2}\right) \\
& \text { s.t. } \frac{z_{2}}{n_{2}}+x_{2} \leq w_{2}+\frac{n_{1}\left(w_{1}-E\left(1 / n_{1}, 1, u_{1}\right)\right)}{n_{2}}
\end{aligned}
$$

which is nothing else than a standard consumer program. Hence, we obtain

$$
\Theta^{e}\left(u_{1}\right)=V\left(\frac{1}{n_{2}}, 1, \frac{\bar{w}-n_{1} E\left(1 / n_{1}, 1, u_{1}\right)}{n_{2}}\right),
$$

where $\bar{w}=n_{1} w_{1}+n_{2} w_{2}$ denotes the aggregate income.

If the utility level of the rich is sufficiently small for the incentive compatibility constraint (11) of the rich to bind, then the public good and tax package $\left(z_{2}^{e b}\left(u_{1}\right), t_{2}^{e b}\left(u_{1}\right)\right)$ of the poor is at the intersection of the two constraints of Program (10):

$z_{2}^{e b}\left(u_{1}\right)=n_{2} t_{2}^{e b}\left(u_{1}\right)+n_{1}\left(w_{1}-E\left(1 / n_{1}, 1, u_{1}\right)\right)$ and $u_{1}=U\left(z_{2}^{e b}\left(u_{1}\right), w_{1}-t_{2}^{e b}\left(u_{1}\right)\right)$.

The only solution that is compatible with all incentive constraints satisfies $z_{2}^{e b}\left(u_{1}\right)<z_{1}^{e b}\left(u_{1}\right)$.

We now characterize the set $\mathcal{U}_{1}$ of utility levels of the rich for which her incentive constraint binds. Denote by $z^{M}\left(1 / n_{2}, 1,\left(\bar{w}-n_{1} E\left(1 / n_{1}, 1, u_{1}\right)\right) / n_{2}\right)$ and $x^{M}\left(1 / n_{2}, 1,\left(\bar{w}-n_{1} E\left(1 / n_{1}, 1, u_{1}\right)\right) / n_{2}\right)$ the Marshallian demands that solve Program (12), and by $t_{2}^{M}\left(1 / n_{2}, 1,\left(\bar{w}-n_{1} E\left(1 / n_{1}, 1, u_{1}\right)\right) / n_{2}\right)=w_{2}-x^{M}$ the tax paid by the poor. The incentive constraint of the rich (11) is binding at the solution of Program (12) if

$u_{1}<U\left(z^{M}\left(\frac{1}{n_{2}}, 1, \frac{\bar{w}-n_{1} E\left(1 / n_{1}, 1, u_{1}\right)}{n_{2}}\right), w_{1}-t_{2}^{M}\left(\frac{1}{n_{2}}, 1, \frac{\bar{w}-n_{1} E\left(1 / n_{1}, 1, u_{1}\right)}{n_{2}}\right)\right)$ 
Since the right-hand side is a continuous and decreasing function of $u_{1}$ (thanks to the normality of the two goods), there exists a (unique) utility level $\bar{u}_{1}^{e b}$ such that (14) holds with equality. For $u_{1}<\bar{u}_{1}^{e b}$, the incentive constraint of the rich binds, and for $u_{1}>\bar{u}_{1}^{e b}$, it does not bind.

The Pareto frontier for the exclusion structure that could be better than no exclusion is then:

$$
\Theta^{e}\left(u_{1}\right)= \begin{cases}V\left(\frac{1}{n_{2}}, 1, \frac{\bar{w}-n_{1} E\left(1 / n_{1}, 1, u_{1}\right)}{n_{2}}\right) & u_{1} \geq \bar{u}_{1}^{e b} \\ U\left(z_{2}^{e b}\left(u_{1}\right), w_{2}-t_{2}^{e b}\left(u_{1}\right)\right) & u_{1}<\bar{u}_{1}^{e b}\end{cases}
$$

for all $u_{1}$ such that $\Theta^{e}$ is decreasing. The function $\Theta^{e}$ is clearly decreasing above $\bar{u}_{1}^{e b}$. However, $\Theta^{e}$ need not be decreasing everywhere below $\bar{u}_{1}^{e b}$. But, using the Envelop Theorem applied to Program 10, we can show that, for $u_{1}$ lower than $\bar{u}_{1}^{e b}$ but sufficiently close to $\bar{u}_{1}^{e b}$, the function $\Theta^{e}$ is decreasing. We also note that incentive compatibility implies that the Pareto frontier $\Theta^{e}$ lies to the right of the $45^{\circ}$ line in the $\left(u_{1}, u_{2}\right)$ space. Since the function $\Theta^{e}$ is negatively sloped at $u_{1}=\bar{u}_{1}^{e b}$, the ideal utility of a poor, $u_{2}^{e *}$, is achieved at a level where the incentive constraint of the rich is strictly binding. The ideal utility level $u_{1}^{e *}$ of the rich depends upon whether the incentive constraint of the poor becomes binding at a utility level below or above the maximal utility $V\left(1 / n_{1}, 1, \bar{w} / n_{1}\right)$ a rich would get if she could tax away all income from the poor jurisdiction. Denote by $\bar{u}_{1}^{e}$ the utility threshold of the rich above which the incentive constraint of the poor becomes binding. The ideal utility level of a rich is then $u_{1}^{e *}=\min \left\{\bar{u}_{1}^{e}, V\left(1 / n_{1}, 1, \bar{w} / n_{1}\right)\right\}$.

Figure 1 illustrates the two frontiers in a situation where the intervals of definition of $\Theta^{n}$ and $\Theta^{e}$ intersect. The green part of the frontier is that where the incentive constraint of the rich does not bind, while the blue part is that where it binds. 


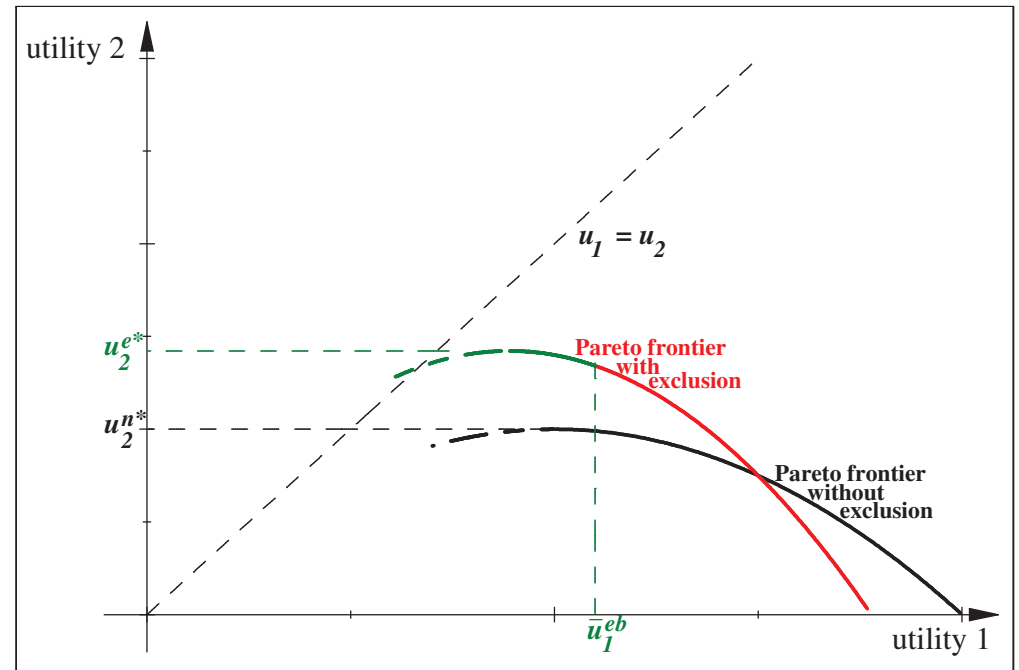

Figure 1: Pareto frontiers of two exclusion structures

\section{The log-log case}

Specific conclusions can be obtained if the individual's utility belongs to the Cobb-Douglas family and writes:

$$
U(z, x)=\ln z+\ln x
$$

This specification is of some importance because, as shown in Gravel and Poitevin (2006), it is the only additive and symmetric between the two goods utility function which, when aggregated by a mean of order $r$ MD, leads this MD to always choose to redistribute money from the rich to the poor jurisdiction in a structure with exclusion where the incentive constraints are satisfied. Another advantage of this specification is that the choice between the two structures mostly depends upon only two parameters: the demographic ratio $a=n_{1} / n_{2}$ of the number of rich over the number of poor, and the interquartile ratio $b=w_{1} / w_{2}$ of the high income over the small one.[5]

Concerning the no-exclusion structure, we observe that the function $\Theta^{n}$ 
writes as: ${ }^{3}$

$$
\Theta^{n}\left(u_{1}\right)=\ln \left[n\left(w_{2}-\left(\frac{w_{1}-\sqrt{w_{1}^{2}-4 e^{u_{1}} / n}}{2}\right)\right)\left(\frac{w_{1}-\sqrt{w_{1}^{2}-4 e^{u_{1}} / n}}{2}\right)\right]
$$

on the relevant domain of definition of $u_{1}$.

Turning now to the structure with exclusion, one obtains, after some manipulations:

$$
\Theta^{e}\left(u_{1}\right):=\left\{\begin{array}{cl}
\ln \left[\frac{\left(\bar{w}-2 n_{1}^{1 / 2} e^{u_{1} / 2}\right)^{2}}{4 n_{2}}\right] & u_{1} \geq \bar{u}_{1}^{e b} \\
\ln \left[\frac{\bar{w}-2 n_{1}^{1 / 2} e^{u_{1} / 2}-n_{2}\left(w_{1}-w_{2}\right)+d\left(u_{1} ; n_{1}, w_{1}, n_{2}\right)}{2 n_{2}}\right]+ & \\
\ln \left[\frac{\bar{w}-2 n_{1}^{1 / 2} e^{u_{1} / 2}+n_{2}\left(w_{1}-w_{2}\right)-d\left(u_{1} ; n_{1}, w_{1}, n_{2}\right)}{2}\right] & u_{1}<\bar{u}_{1}^{e b}
\end{array}\right.
$$

where

$$
d\left(u_{1} ; n_{1}, w_{1}, n_{2}\right)=\sqrt{4 e^{u_{1}}\left(n_{1}-n_{2}\right)-4 \sqrt{n_{1} e^{u_{1}}} w_{1} n+w_{1}^{2} n^{2}} .
$$

A look at $\Theta^{n}$ and $\Theta^{e}$ provided by (16) and (17) suggests that the optimality of exclusion based only on Pareto dominance cannot be made in general. The choice of the optimal exclusion structure depends crucially upon the specific social welfare function used. In what follows, we focus on two specific social welfare functions: Maxmin and Utilitarianism.

A Maxmin MD seeks to maximize the utility of the worst off agent. As noticed above, whatever is the structure, any efficient allocation satisfying the incentive constraint of the rich provides the rich with utility strictly larger than that of the poor. Hence, a Maxmin MD maximizes the utility of the poor. The designer therefore compares the utility level $u_{2}^{n *}$ with the ideal utility $u_{2}^{e^{*}}$ of the poor in a structure with exclusion. The expression for the difference $u_{2}^{e^{*}}-u_{2}^{n *}$ depends on all four parameters and is somewhat messy. However, the difference $\Theta^{e}\left(\bar{u}_{1}^{e b}\right)-u_{2}^{n *}$ only depends on the parameters $a$ and $b$. Since $u_{2}^{e^{*}}>\Theta^{e}\left(\bar{u}_{1}^{e b}\right)$, the latter difference underestimates the region where exclusion is favored. We

\footnotetext{
${ }^{3}$ We use Mathematica to perform computations. The code is available upon request.
} 
then use it for illustrative purposes. We can show that $\Theta^{e}\left(\bar{u}_{1}^{e b}\right)-u_{2}^{n *}>0$ if and only if $b$ is strictly larger than the fourth root of the following polynomial

$$
x^{4} a^{3}+4 x^{3} a^{2}+x^{2}\left(-2 a^{3}-16 a^{2}-8 a\right)+x\left(12 a^{2}-8\right)+a^{3}-4 a^{2}+4 .
$$

Figure 2 shows in black the set of values of $a$ and $b$ such that $b$ is equal to this root. As argued above, this curve lies above the true curve of indifference between the two jurisdiction structures based on the difference $u_{2}^{e^{*}}-u_{2}^{n *}$. For any $a$, there is a large enough $b$ for which exclusion is favored. The relevant root of the polynomial (18) is decreasing in $a$ so that, for a fixed income ratio $b$, an increase in $a$ makes exclusion more valuable socially. When the relative number of rich or their relative income increases, it becomes more beneficial socially to cross subsidize. The MD then favors the exclusion structure despite the cost of duplicating the public good.

We now consider the Utilitarian objective. The maximized sum of utilities in the no-exclusion structure $\left(W_{u t i l}^{n}\right)$ can be shown to be:

$$
\begin{aligned}
W_{u t i l}^{n}= & n_{2} \ln \left[\frac{g\left(n_{1}, n_{2}, w_{1}, w_{2}\right)-n_{1} w_{1}+2 n_{1} w_{2}-2 n_{2} w_{1}+3 n_{2} w_{2}}{4 n}\right]+ \\
& n_{1} \ln \left[\frac{g\left(n_{1}, n_{2}, w_{1}, w_{2}\right)+3 n_{1} w_{1}-2 n_{1} w_{2}+2 n_{2} w_{1}-n_{2} w_{2}}{4 n}\right]+ \\
& n \ln \left[\frac{1}{4}\left(-g\left(n_{1}, n_{2}, w_{1}, w_{2}\right)+n_{1} w_{1}+2 n_{1} w_{2}+2 n_{2} w_{1}+n_{2} w_{2}\right)\right]
\end{aligned}
$$

where $g\left(n_{1}, n_{2}, w_{1}, w_{2}\right)=\sqrt{\left(n_{1} w_{1}+2 n_{1} w_{2}+2 n_{2} w_{1}+n_{2} w_{2}\right)^{2}-8 w_{1} w_{2} n^{2}}$.

The optimal allocation for the exclusion structure is the solution to:

$$
\begin{array}{cl}
\max _{z_{1}, t_{1}, z_{2}, t_{2}} & n_{1}\left[\ln \left(w_{1}-t_{1}\right)+\ln z_{1}\right]+n_{2}\left[\ln \left(w_{2}-t_{2}\right)+\ln \left(z_{2}\right)\right] \\
\text { s.t. } & z_{1}+z_{2} \leq n_{1} t_{1}+n_{2} t_{2} \\
& \ln \left(w_{1}-t_{1}\right)+\ln z_{1} \geq \ln \left(w_{1}-t_{2}\right)+\ln z_{2} .
\end{array}
$$

We first compute the solution to Program (19) when the incentive constraint is not binding. We then evaluate the incentive constraint at this solution. It can be shown that the incentive constraint is not binding when:

$$
a^{2} b-3(b-1) a+1-2 b \geq 0 .
$$

If condition (20) holds, then the maximized sum of utilities in a structure with 
exclusion, denoted $W_{u t i l}^{e}$, is:

$$
W_{u t i l}^{e}=2 n_{1} \ln \left[\frac{n_{1} \bar{w}}{n}\right]+2 n_{2} \ln \left[\frac{n_{2} \bar{w}}{n}\right]-n_{1} \ln \left[4 n_{1}\right]-n_{2} \log \left[4 n_{2}\right] .
$$

It turns out that the difference $W_{u t i l}^{e}-W_{u t i l}^{n}$ depends only on $a$ and $b$. Figure 2 provides a geometrical depiction of the combinations of $(a, b)$ ratios for which exclusion is normatively desirable for the Utilitarian MD. A similar intuition as before arises. When $a$ or $b$ increases, cross subsidization becomes socially more desirable and hence exclusion is favored. Furthermore, as the heterogeneity increases, the Utilitarian MD prefers to exclude so as to adapt the public good provision to the individuals' tastes.

We observe that a Maxmin MD will always favor exclusion when a Utilitarian MD does. The reason for the stronger preference for exclusion exhibited by the Maxmin MD comes from the distribution possibilities between the rich and the poor that subsidization across jurisdictions opens up. As a matter of fact, a Maxmin MD would never choose a jurisdiction structure with exclusion if it was not allowed to cross subsidize. However, a Utilitarian MD could, under some circumstances, prefer exclusion over non exclusion. For this to happen, it is necessary that the two incentive constraints be satisfied when each jurisdiction is implementing its optimal autarkic public good and tax package. In such a case, if the income difference between rich and poor is sufficiently large, the Utilitarian MD could favor exclusion over non exclusion. The driving force for this preference would then be the match of the public good and tax packages to the tastes of the two types rather than the redistributive motive. On Figure 2, we have shown in purple the set of values of $a$ and $b$ at the north east of which a Utilitarian MD would favor exclusion in the case where cross subsidization is ruled out. 


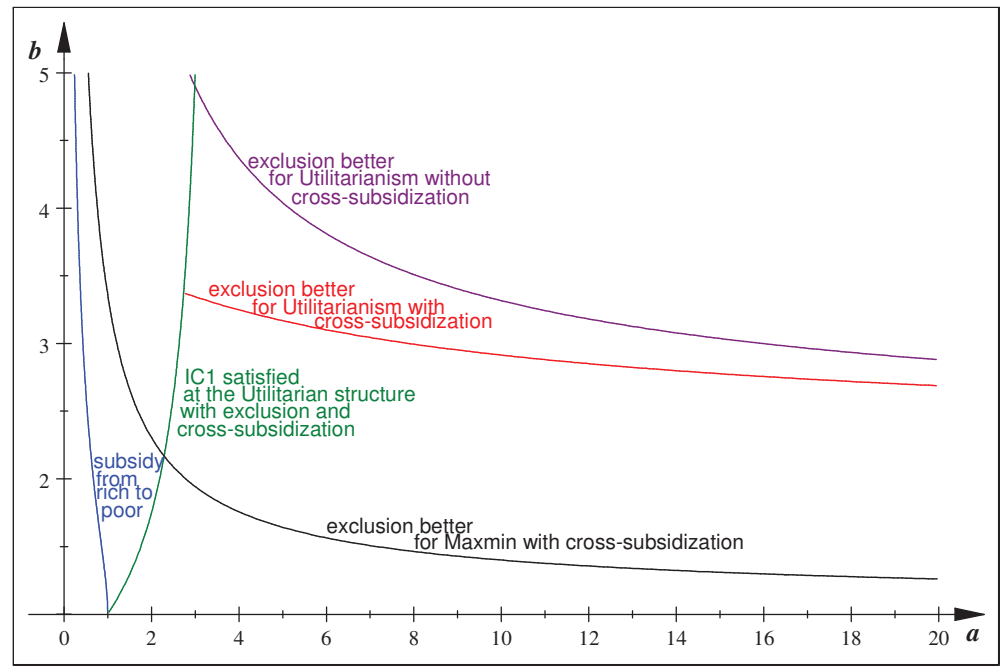

Figure 2: Comparison of the exclusion structures for Utilitarian and Maxmin social welfare functions, with and without cross-subsidization

Unfortunately, the two-dimensional feature of the analysis in $(a, b)$-space is lost when the incentive constraint of the rich is binding at the solution of Program (19). For we cannot extend the red curve in Figure 2 to the northwest of the incentive constraint (green) curve. In this case, the choice between the two structures depends upon all four parameters $\left(n_{1}, n_{2}, w_{1}, w_{2}\right)$, and not only upon the ratios $a$ and $b$. We can nonetheless state results about the set of values of the parameters that would lead the Utilitarian MD to favor exclusion in the case where the incentive constraint binds at the Utilitarian solution. For this sake, we rewrite Program (19) as:

$$
\max _{s} n_{1} \ln \left[\frac{\left(w_{1}-s / n_{1}\right)^{2} n_{1}}{4}\right]+n_{2}\left[\ln \left(s+n_{2} t_{2}(s)\right)+\ln \left(w_{2}-t_{2}(s)\right]\right.
$$

where $t_{2}(s)$ is defined implicitly by the incentive constraint:

$$
\ln \left(s+n_{2} t_{2}(s)\right)+\ln \left(w_{1}-t_{2}(s)\right)=\ln \left[\frac{\left(w_{1}-s / n_{1}\right)^{2} n_{1}}{4}\right] .
$$

The variable $s$ can be interpreted as the aggregate (possibly negative) subsidy given by the rich to the poor in excess of what is required to finance their public good consumption. The solution $\widehat{s}$ to Program (21) satisfies the first-order 
condition:

$$
\frac{-2}{n_{1}\left(w_{1}-\widehat{s} / n_{1}\right)}+n_{2}\left(\frac{n_{2}}{\left.\widehat{s}+n_{2} t_{2}(\widehat{s})\right)} \frac{d t_{2}(\widehat{s})}{d s}-\frac{1}{w_{2}-t_{2}(\widehat{s})} \frac{d t_{2}(\widehat{s})}{d s}\right)=0 .
$$

There are values of $\left(w_{1}, w_{2}, n_{1}, n_{2}\right)$ for which $\widehat{s}=0$. Furthermore, the set of parameters for which this is the case depends only upon $a$ and $b$. This set is bounded by the equality (defined only if $a \in] 0,1]$ ):

$$
b=\frac{\sqrt{1-a}+2 a}{2 a-a \sqrt{1-a}} .
$$

It is easy to see that $b$ goes to infinity when $a$ becomes negligible. On Figure 2, we have plotted (in blue) the curve described by equation (22). For all values of $a$ and $b$ to the right (left) of this line, the optimal subsidy is positive (negative). When $a$ is very small, there are very few rich individuals and, hence, their implicit price for the public good is very large relative to that for the poor. Consequently, the amount of public good provided for the rich is small. This implies that the optimal subsidy from the rich to the poor must be negative in order to prevent the rich from moving to the poor jurisdiction.

As it turns out, if the optimal subsidy chosen by the Utilitarian MD for the exclusion structure is 0 , then it is never optimal to exclude. This means that, in Figure 2, an appropriately extended red curve would never cross the blue one. We state this formally as follows.

Proposition 2. Suppose that condition (22) is satisfied so that the solution to Program (21) is $\widehat{s}=0$. Then the Utilitarian MD chooses not to exclude.

From this Proposition, one concludes that, for a Utilitarian MD, the region of social indifference between exclusion and no-exclusion is located somewhere between the blue curve for which $\widehat{s}=0$ and the green curve where the incentive constraint of the rich barely binds. This suggests that for any given demographic ratio $a$ however small, there exists a high enough interquartile ratio $b$ above which the MD always prefers to exclude. Figure 2 does not provide insight about the validity of this intuition because what happens between the IC green curve and the blue curve does not depend only upon the ratios $a$ and $b$. It depends upon the four parameters $\left(w_{1}, w_{2}, n_{1}, n_{2}\right)$. However, the following Proposition shows that this intuition is correct.

Proposition 3. For any value of $a$ at which the incentive constraint of the rich binds, there exists a large enough $b$ at which the Utilitarian MD prefers the structure with exclusion. 


\section{Conclusion}

We consider a form of exclusion for which the only way by which two individuals can consume two different quantities of a non-rival public good is by financing the sum of the cost of the two quantities. We have shown that if the MD is imperfectly informed about the willingness to pay of its citizens, it may find optimal to offer to different individuals different quantities of the public good, and to bear the cost of replicating the public good. This comes from the information that the MD obtains from having individuals "choosing" their favorite tax and public good packages. Exclusion therefore achieves a better targeting to the preferences of individuals. Our analysis shows that the benefit of this better targeting may outweigh the cost of unnecessarily replicating the provision of a non-rival public good. We have shown in particular that the preference for such a costly exclusion is more likely as the rich are more populous or richer and, in the $\log -\log$ case, when the social aversion to utility inequality is important.

Our analysis suffers from at least two limitations. The first one is its restriction to individuals who differ only in contributive capacities (income), and who have the same preferences for the private and the public goods. An alternative would have been to consider individuals with the same income, but with different tastes for the public good. We conjecture that a similar qualitative conclusion would have held in this case. A more realistic, but analytically much more challenging, situation would have been with individuals differing both in their income and their preferences.

The second limitation is the restriction of our analysis to a two-type setting. Even though Proposition (1) holds for an arbitrary finite number of types, it would be difficult to characterize further the problem of the optimal choice of a jurisdiction structure under private information. Imagine for instance a threetype setting. Then, one would need to consider many jurisdiction structures: no-exclusion, complete exclusion, and two incompletely excluded structures: one where the rich are pooled with the "middle" in one jurisdiction and the poor are left alone, and the other where the rich stay alone and the "middle" and the poor form a jurisdiction. Thanks to the single crossing property, these would be the only exclusion structures that would qualify for Pareto optimality. But the analysis of all of these cases, with all the varying possibilities for the incentive constraints to bind or not, would have been very tedious. 


\section{Appendix A. Appendix}

\section{Appendix A.1. Proof of Proposition 1}

1. This follows from the single-crossing property and the incentive constraints. It can be shown using Theorem 4 in Athey (2002).

2. Suppose two jurisdictions $j$ and $j^{\prime}$ had $z_{j}^{*}=z_{j^{\prime}}^{*}$. Incentive compatibility means that $t_{j}^{*}=t_{j^{\prime}}^{*}$. If the MD merges the two jurisdictions, it can avoid duplicating the cost of the public good and use the extra taxes to operate a Pareto improvement.

3. Let $\left\{N_{1}^{*}, N_{2}^{*}\right\}$ be an exclusion structure with public goods and taxes $\left(z_{j}^{*}, t_{j}^{*}\right)$ for $j=1,2$ that maximizes the function $\Psi$ defined by Program (3) and is such that $N_{j}^{*}=\left\{i \in N: w^{i}=w_{j}\right\}$ for $j=1,2$. By contradiction, assumes that $z_{1}^{*}>z_{2}^{*}$ and $U\left(z_{1}^{*}, w_{2}-t_{1}^{*}\right)=U\left(z_{2}^{*}, w_{2}-t_{2}^{*}\right)$. This equality can only holds if $t_{1}^{*}>t_{2}^{*}$. Consider then moving all poor individuals from $N_{2}^{*}$ to $N_{1}^{*}$. This move would be a matter of indifference for them. It would clearly not affect the quantity of public good and tax payments of the rich in the set $N_{1}^{*}$. Since everybody will now pay the tax $t_{1}^{*}>t_{2}^{*}$, the MD would obtain the tax revenues $\left(t_{1}^{*}-t_{2}^{*}\right) n_{2}>0$ that it could use to realize Pareto improvements. But this contradicts $\left\{N_{1}^{*}, N_{2}^{*}\right\}$ being an exclusion structure that maximizes $\Psi$.

\section{Appendix A.2. Proof of Proposition 2}

Assume that the incentive constraint of the rich is binding and that the optimal subsidy $\widehat{s}=0$. In this case, (1) the rich is indifferent between its allocation and that of the poor, and (2) the tax paid by the poor covers the totality of the cost of its own public good. In this case, the Utilitarian MD can improve on the structure with exclusion. Suppose that the rich is pooled in the jurisdiction of the poor. The rich is indifferent to this change, and the same level of public good can be provided since it can be solely financed byt the taxes paid by the poor. The MD can then operate a Pareto improving change using the taxes collected from the rich. Hence, the no exclusion structure dominates that with exclusion. Note that this argument is general and does not depend on the log-log preferences.

\section{Appendix A.3. Proof of Proposition 3}

One needs to compute the difference $W_{u t i l}^{e}-W_{u t i l}^{n}$. The difficulty lies in characterizing the optimal level of subsidy $\widehat{s}$ chosen in the federal structure by a Utilitarian MD when the incentive constraint binds. Instead of doing so, we 
compute the social welfare difference using the subsidy that would be chosen by the MD if it were facing no incentive constraint. Since this subsidy is suboptimal when the incentive constraint of the rich binds, this computation underestimates the difference $W_{u t i l}^{e}-W_{u t i l}^{n}$. Define

$$
x(a, b)=\sqrt{a^{2}\left(4 b^{2}-6 b+1\right)-a^{3} b^{2}+a\left(4 b^{2}-2 b-1\right)+b^{2}} .
$$

Using Mathematica, we get:

$$
\begin{gathered}
\frac{W_{u t i l}^{e-p s e u d o}-W_{u t i l}^{n}}{n_{2}}=2 a \ln \left[\frac{a n_{2} w_{2}(a b+1)}{a+1}\right]-a \ln \left[4 a n_{2}\right]+ \\
\ln \left[\frac{n_{2} w_{2}(x(a, b)+a-b+2)(x(a, b)-2 a b+a-b)}{(a+1)\left(a b-\sqrt{(a(b+2)+2 b+1)^{2}-8 b(a+1)^{2}}-2 a+2 b-3\right)}\right]- \\
(a+1) \ln \left[\frac{1}{4} n_{2} w_{2}\left(a b-\sqrt{(a(b+2)+2 b+1)^{2}-8 b(a+1)^{2}}+2 a+2 b+1\right)\right]- \\
a \ln \left[\frac{w_{2}\left(\sqrt{(a(b+2)+2 b+1)^{2}-8 b(a+1)^{2}}+3 a b-2 a+2 b-1\right)}{4(a+1)}\right],
\end{gathered}
$$

where $W_{u t i l}^{e-p s e u d o}$ refers to the 2 nd best Utilitarian social welfare with the (suboptimal) subsidy solving:

$$
\max _{s} n_{1} V\left(1 / n_{1}, 1, w_{1}-s / n_{1}\right)+n_{2} V\left(1 / n_{1}, 1, w_{1}-s / n_{1}\right)
$$

It turns out that the partial derivatives of this expression with respect to $n_{2}$ and $w_{2}$ is equal to 0 . Consequently, the sign of this expression only depends on the ratios $a$ and $b$. We then set $w_{2}=n_{2}=1$. Fixing the ratio $a$ and taking the limit of $W_{u t i l}^{e-p s e u d o}-W_{u t i l}^{n}$ when $b$ goes to infinity, we can show that this difference goes to infinity. This implies that, for any demographic ratio $a$, there exists a high enough interquartile ratio $b$ such that exclusion is socially preferable to no-exclusion. 
Acknowledgements: This paper originates from an earlier paper entitled "Should a non-rival public good be provided centrally?". We acknowledge with gratitude the financial support of the grant of the French Agency for Scientific Research (ANR contract STRAT-INEQ) and SSHRC. We are also indebted, with the usual disclaiming qualification, to Francis Bloch, Massimo Bordignon, Dennis Epple, Pierre Pestieau, Alain Trannoy, Tanguy Van Ypersele, two anonymous referees and the associate editor of the journal for their useful comments and suggestions.

[1] Athey, S. (2002): "Comparative Statics Under Uncertainty," Quarterly Journal of Economics, 117, 187-223.

[2] Drèze, J. (1980): "Public Goods with Exclusion," Journal of Public Economics, 13, 5-24.

[3] Fang, H., and P. Norman (2010): "Optimal Provision of Excludable Public Goods," American Economic Journal: Microeconomics, 2, 1-37.

[4] Fraser, C. D. (1996): "On the Provision of Excludable Public Goods," Journal of Public Economics, 60, 111-130.

[5] Gravel, N., and M. Poitevin (2006): "The Progressivity of Equalization Payments in Federations," Journal of Public Economics, 90, 1725-1743.

[6] Hellwig, M. F. (2003): "Public Good Provision with Many Participants," Review of Economic Studies, 70, 589-614.

[7] (2005): "A Utilitarian Approach to the Provision and Pricing of Excludable Public Goods," Journal of Public Economics, 89, 1981-2003.

[8] _ (2007): "The Provision and Pricing of Excludable Public Goods: Ramsey-Boiteux Pricing versus Bundling," Journal of Public Economics, 91, $511-540$.

[9] Moulin, H. (1994): "Serial Cost Sharing of Excludable Public Goods," Review of Economic Studies, 61, 305-325.

[10] Norman, P. (2004): "Efficient Mechanisms for Public Goods with Use Restrictions," Review of Economic Studies, 71, 1163-1188. 